\title{
A escrita criativa nos cursos de pós-graduação strictu sensu das universidades brasileiras
}

\author{
Marcelo Spalding Perez* \\ Luiz Antonio de Assis Brasil e Silva"
}

\section{Resumo}

Temos visto no Brasil uma demanda crescente por cursos e livros de escrita criativa na última década. Resta, porém, investigar se essa demanda crescente se reflete em maior presença nas universidades brasileiras, especificamente nos cursos de pós-graduação strictu sensu, nos quais se dá a maior parte da pesquisa e da produção de conhecimento no Brasil. Para tal pesquisa, foram analisados 28 programas de pós-graduação com nota acima de 5 na Avaliação Quadrienal 2017 da Capes. Também se buscou no Banco de Teses e Dissertações da Capes trabalhos em que a expressão "escrita criativa" aparecesse no título. Ao final, a hipótese inicial de crescimento da presença formal nos cursos de pós-graduação no Brasil foi frustrada, o que pode estar relacionado com a persistente crença de que a escrita é um dom restrito a gênio iluminados.

Palauras-chave: Escrita criativa. Ensino de escrita criativa. Escrita criativa nas universidades brasileiras.

\section{O ensino de escrita criativa no Brasil}

Poderíamos dizer que a discussão sobre oficinas de escrita criativa - e por extensão sobre cursos universitários de escrita criativa - já passou da primeira fase no Brasil, quando se questionava a possibilidade de alguém aprender algo tão "intuitivo" quanto escrever um bom texto literário ou as oficinas eram acusadas de padronizar os textos dos oficinandos. Segundo Assis Brasil (2015, p. 105), tal desconfiança gerou uma série de equívocos e inclusive atrasou a implementação dos literary workshops de estilo norte-americano no país, entretanto "a geração de escritores que começou

\footnotetext{
Pontifícia Universidade Católica do Rio Grande do Sul (PUCRS). Pós-doutorando da Pontifícia Universidade Católica do Rio Grande do Sul (PUCRS). E-mail: marcelospalding@gmail.com

** Pontifícia Universidade Católica do Rio Grande do Sul / PUCRS. Professor Titular da Pontifícia Universidade Católica do Rio Grande do Sul (PUCRS).E-mail: laab@ pucrs.br
}

Data de submissão: jan. 2018 - Data de aceite: jun. 2018 http://dx.doi.org/10.5335/rdes.v14i2.7864 
a publicar a partir dos anos 2000 tem outra postura, bem mais aberta e disponível a experiências, e dispensa, de bom grado, a ideia de luta e sofrimento". Ainda segundo o professor,

[...] o que melhor evidencia esse fenômeno de ultrapassagem é o fato evidente de que a maioria desses novos autores originou-se das oficinas literárias - tal como acontece nos Estados Unidos já desde a década de sessenta do século anterior, dos quais o nome emblemático é Raymond Carver - e não poucos tornam-se, eles mesmos, ministrantes de oficinas (ASSIS BRASIL, 2015, p. 105).

Assim, desde a última década, os cursos de escrita criativa no país têm tido uma demanda expressiva e sempre maior a cada ano, chegando a disciplinas de graduação e formação integral de mestrado e doutorado, na Pontifícia Universidade Católica do Rio Grande do Sul (PUCRS) (ASSIS BRASIL, 2015). Também encontramos artigos e notícias de jornal dos últimos anos que abordam o crescimento da disciplina na academia.

A reportagem "Universidades integram oficinas de escrita criativa ao currículo", publicada no Terra em 2012, aborda especificamente "cursos de graduação, extensão e qualificação profissional voltados à capacitação de quem se interessa pelo processo de construção, interpretação e avaliação de uma obra literária”. A reportagem faz um histórico das oficinas nos Estados Unidos, men- ciona uma antiga experiência de Ciro dos Anjos, de 1962, na Universidade de Brasília, debate ainda a possibilidade de se escrever melhor a partir de uma Oficina Literária e menciona a Oficina de Criação Literária da PUCRS como marco no país. Ao final, faz menção a um bacharelado em Letras com habilitação em Produção Textual, curso oferecido pela PUC-Rio desde 2004:

No currículo, são combinados os conhecimentos básicos do curso de Letras, como Língua Portuguesa, Linguística e Literatura, a uma série de oficinas sob o formato de disciplinas opcionais, divididas em gêneros literários (poesia, roteiro, dramaturgia) e não literários (lexicografia, texto institucional e texto editorial). "A ideia é que o aluno faça seu próprio recorte dentro das ofertas", explica Paulo Henriques Britto, professor e supervisor da habilitação. Britto, que também é escritor e tradutor literário, conta que, além dos professores da universidade, as aulas são ministradas também por profissionais de cada ramo. "Pretendemos contratar escritores que, durante um semestre, possam ministrar a oficina voltada especificamente para o trabalho dele, como romancistas, poetas e roteiristas", afirma (TERRA, 2012).

Em Pernambuco, a reportagem "A ainda tímida relação entre cursos de Letras e a escrita criativa", publicada em 2014 por Diogo Guedes, defende que "mesmo com crescimento de graduação 
e pós em áreas de criação literária, a academia ainda pode se beneficiar com proximidade das técnicas de escrita". A partir de uma entrevista com Raimundo Carrero, apontado como um dos pioneiros entre os professores de escrita literária, a reportagem atribui à resistência dos Departamentos de Letras o descompasso entre o que acontece no Brasil e nos Estados Unidos, faz menção a cursos de especialização na área em São Paulo e Rio de Janeiro e lamenta a resistência da própria UFPE:

Cursos como a formação em Produção Textual, pela PUC-Rio, ou a pós-graduação em Formação de Escritores do ISE Vera Cruz, em São Paulo, são uma realidade para quem quiser se dedicar ao ofício da escrita. Apesar disso, ainda não chegaram aos Departamentos de Letras da maioria das universidades públicas, e em alguns nem mesmo como parte do curso. A UFPE, por exemplo, tem prevista na sua ementa uma cadeira de Criação Literária, mas sem incluir produção de textos (GUEDES, 2014).

Também a reportagem Estímulo à criação ainda precisa evoluir, reproduzida pelo site da UFPE, aborda frontalmente a questão da escrita criativa nas universidades pernambucanas. Com a linha de apoio "Barreiras no pensamento acadêmico e a falta de pesquisas na área travam o avanço do ensino da escrita criativa nos cursos de Letras das universidades brasileiras", a matéria entrevista o professor do departamento de Letras da UFPE Lourival Holanda, que critica o receio de incentivar a produção de textos dentro dos cursos e ressalta o crescimento da escrita criativa em todo o país: “mesmo a Pós-Graduação em Letras da UFPE já teve trabalhos defendidos na área. Lourival aponta como exemplo local o trabalho de Carlos Newton Jr., que romanceou o mundo armorial na sua tese de doutorado, mas ressalta que é um caso raro" (UFPE, 2017, sem paginação).

Também de 2014 é a reportagem Cursos de pós-graduação prometem formar escritores, do Estado de S. Paulo. A matéria de Marcelo Lima aborda o curso de Formação de Escritores do Instituto de Ensino Superior Vera Cruz. Segundo Lima (2014), ao entrar na pós, o escritor deve escolher uma área de concentração - ficção, não ficção ou poesia -, e a partir de 2015 poderia optar também pela especialização em professor de criação literária, dedicada aos escritores que também desejam ensinar o ofício.

No Rio Grande do Sul, por ocasião do lançamento do curso superior de tecnologia em Escrita Criativa, a Zero Hora publicou em 2015 uma matéria abordando o pioneirismo da PUCRS na oferta de cursos acadêmicos na área. A reportagem de Juliana Forner explica a diferença entre o curso de Letras e o de Escrita Criativa, trazendo depoimento de professores e estudantes da instituição e retomando a história da Oficina de Criação Literária da PUCRS, além de listar alguns programas de instituições nos Estados Unidos e na Inglaterra que oferecem o curso.

Não menos revelador da crescente demanda pelo tema é o surgimento de 
diversos livros brasileiros sobre o tema, como Escreva: guia de escrita criativa (2015), de Jane Tutikian e Pedro Gonzaga, Criação literária: da ideia ao texto (2015), de José Carlos Laitano, Oficina de escrita criativa (2013), de Solimar Silva, A poética do conto (2013), de Charles Kiefer, Escrita criativa: o prazer da linguagem (2008), de Renata di Nizo, e A oficina do escritor: sobre ler, escrever e publicar (2008), de Nelson de Oliveira, além de obras traduzidas como Romancista como vocação (2017), de Haruki Murakami, Sobre a escrita (2015), de Stephen King, Palavra por palavra: instruções sobre escrever e viver (2011), de Anne Lamott, A arte da ficção (2009), de David Lodge, A louca da casa (2008), de Rosa Montero, ou Cartas a um jovem escritor (2006), de Mario Vargas Llosa.

Resta, porém, investigar se essa demanda crescente por cursos de escrita criativa se reflete em maior presença nas universidades brasileiras, especificamente nos cursos de pós-graduação strictu sensu, aos quais se liga a maior parte da pesquisa e da produção de conhecimento no Brasil.

\section{Metodologia}

Para fins de seleção da amostra, utilizamos tabela disponibilizada pela própria Capes ${ }^{1}$ com o seguinte filtro: Área de Avaliação: Letras/Linguística; Nota do Curso na Avaliação Quadrienal 2017: 5, 6 ou 7; Modalidade: Acadêmico.

A partir daí, foram excluídos os programas cuja Área Básica fosse "linguística" e o Programa trouxesse apenas o termo "estudos da tradução" ou "linguística". Nos casos em que havia "linguística" e outro termo, como na PUCRS, acessamos as Áreas de Concentração e excluímos aqueles em que essas eram apenas de linguística e ensino de língua portuguesa. Optou-se por manter os cursos em cujo Programa conste "Linguística Aplicada". Chegamos, assim, aos 28 programas listados a seguir (por ordem de Nota do Curso e Ordem Alfabética da Instituição de Ensino) que compõem o corpus dessa pesquisa: 
Quadro 1 - Relação de programas de Pós-Graduação em Letras com conceito acima de 5 que constituem o corpus da pesquisa

\begin{tabular}{|c|c|c|c|c|c|}
\hline Programa & Instituição de Ensino & Área de Avaliação & Área Básica & M & $\mathrm{D}$ \\
\hline LINGUÍSTICA E LETRAS & $\begin{array}{l}\text { PONTIFÍCIA UNIVERSIDADE CATÓLICA } \\
\text { DO RIO GRANDE DO SUL }\end{array}$ & $\begin{array}{l}\text { LETRAS / } \\
\text { LINGUÍSTICA }\end{array}$ & LINGUÍSTICA & 7 & 7 \\
\hline $\begin{array}{l}\text { TEORIA E HISTÓRIA } \\
\text { LITERÁRIA }\end{array}$ & $\begin{array}{l}\text { UNIVERSIDADE ESTADUAL DE } \\
\text { CAMPINAS }\end{array}$ & $\begin{array}{l}\text { LETRAS / } \\
\text { LINGUÍSTICA }\end{array}$ & LETRAS & 7 & 7 \\
\hline ESTUDOS LITERÁRIOS & $\begin{array}{l}\text { UNIVERSIDADE FEDERAL DE MINAS } \\
\text { GERAIS }\end{array}$ & $\begin{array}{l}\text { LETRAS / } \\
\text { LINGUÍSTICA }\end{array}$ & LETRAS & 7 & 7 \\
\hline LETRAS & $\begin{array}{l}\text { UNIVERSIDADE FEDERAL DO RIO } \\
\text { GRANDE DO SUL }\end{array}$ & $\begin{array}{c}\text { LETRAS / } \\
\text { LINGUÍSTICA }\end{array}$ & LETRAS & 7 & 7 \\
\hline ESTUDOS LITERÁRIOS & $\begin{array}{l}\text { UNIVERSIDADE EST.PAULISTA JÚLIO DE } \\
\text { MESQUITA FILHO/ARARAQUARA }\end{array}$ & $\begin{array}{c}\text { LETRAS / } \\
\text { LINGUÍSTICA }\end{array}$ & LETRAS & 6 & 6 \\
\hline LETRAS & $\begin{array}{l}\text { UNIVERSIDADE EST.PAULISTA JÚLIO DE } \\
\text { MESQUITA FILHO/SJR. PRETO }\end{array}$ & $\begin{array}{l}\text { LETRAS / } \\
\text { LINGUÍSTICA }\end{array}$ & LETRAS & 6 & 6 \\
\hline LETRAS & UNIVERSIDADE FEDERAL DO PARANÁ & $\begin{array}{c}\text { LETRAS / } \\
\text { LINGUÍSTICA }\end{array}$ & LETRAS & 6 & 6 \\
\hline $\begin{array}{l}\text { LETRAS (LETRAS } \\
\text { VERNÁCULAS) }\end{array}$ & $\begin{array}{l}\text { UNIVERSIDADE FEDERAL DO RIO DE } \\
\text { JANEIRO }\end{array}$ & $\begin{array}{c}\text { LETRAS / } \\
\text { LINGUÍSTICA }\end{array}$ & LETRAS & 6 & 6 \\
\hline Estudos de Literatura & UNIVERSIDADE FEDERAL FLUMINENSE & $\begin{array}{c}\text { LETRAS / } \\
\text { LINGUÍSTICA }\end{array}$ & LETRAS & 6 & 6 \\
\hline LETRAS & $\begin{array}{l}\text { UNIVERSIDADE PRESBITERIANA } \\
\text { MACKENZIE }\end{array}$ & $\begin{array}{l}\text { LETRAS / } \\
\text { LINGUÍSTICA }\end{array}$ & LETRAS & 6 & 6 \\
\hline LETRAS & Fundação Universidade de Passo Fundo & $\begin{array}{c}\text { LETRAS / } \\
\text { LINGUÍSTICA }\end{array}$ & LETRAS & 5 & 5 \\
\hline LETRAS & $\begin{array}{l}\text { PONTIFÍCIA UNIVERSIDADE CATÓLICA } \\
\text { DE MINAS GERAIS }\end{array}$ & $\begin{array}{c}\text { LETRAS / } \\
\text { LINGUÍSTICA }\end{array}$ & $\begin{array}{l}\text { LITERATURA } \\
\text { BRASILEIRA }\end{array}$ & 5 & 5 \\
\hline LÍNGUA PORTUGUESA & $\begin{array}{l}\text { PONTIFÍCIA UNIVERSIDADE CATÓLICA } \\
\text { DE SÃO PAULO }\end{array}$ & $\begin{array}{l}\text { LETRAS / } \\
\text { LINGUÍSTICA }\end{array}$ & $\begin{array}{c}\text { LÍNGUA } \\
\text { PORTUGUESA }\end{array}$ & 5 & 5 \\
\hline $\begin{array}{l}\text { LINGUÍSTICA APLICADA E } \\
\text { ESTUDOS DA LINGUAGEM }\end{array}$ & $\begin{array}{l}\text { PONTIFÍCIA UNIVERSIDADE CATÓLICA } \\
\text { DE SÃO PAULO } \\
\end{array}$ & $\begin{array}{c}\text { LETRAS / } \\
\text { LINGUÍSTICA }\end{array}$ & $\begin{array}{l}\text { LINGUÍSTICA } \\
\text { APLICADA }\end{array}$ & 5 & 5 \\
\hline $\begin{array}{l}\text { LITERATURA, CULTURA E } \\
\text { CONTEMPORANEIDADE }\end{array}$ & $\begin{array}{l}\text { PONTIFÍCIA UNIVERSIDADE CATÓLICA } \\
\text { DO RIO DE JANEIRO }\end{array}$ & $\begin{array}{c}\text { LETRAS / } \\
\text { LINGUÍSTICA }\end{array}$ & LETRAS & 5 & 5 \\
\hline LETRAS & UNIVERSIDADE CATÓLICA DE PELOTAS & $\begin{array}{l}\text { LETRAS / } \\
\text { LINGUÍSTICA }\end{array}$ & $\begin{array}{l}\text { LINGUÍSTICA } \\
\text { APLICADA }\end{array}$ & 5 & 5 \\
\hline LITERATURA & UNIVERSIDADE DE BRASÍLIA & $\begin{array}{c}\text { LETRAS / } \\
\text { LINGUÍSTICA } \\
\end{array}$ & LETRAS & 5 & 5 \\
\hline $\begin{array}{l}\text { LETRAS (TEORIA } \\
\text { LITERÁRIA E LITERATURA } \\
\text { COMPARADA) }\end{array}$ & UNIVERSIDADE DE SÃO PAULO & $\begin{array}{l}\text { LETRAS / } \\
\text { LINGUÍSTICA }\end{array}$ & TEORIA LITERARIA & 5 & 5 \\
\hline LETRAS & $\begin{array}{l}\text { UNIVERSIDADE DO ESTADO DO RIO DE } \\
\text { JANEIRO }\end{array}$ & $\begin{array}{l}\text { LETRAS / } \\
\text { LINGUÍSTICA }\end{array}$ & LETRAS & 5 & 5 \\
\hline LINGÜÍSTICA APLICADA & $\begin{array}{l}\text { UNIVERSIDADE DO VALE DO RIO DOS } \\
\text { SINOS }\end{array}$ & $\begin{array}{c}\text { LETRAS / } \\
\text { LINGUÍSTICA }\end{array}$ & $\begin{array}{l}\text { LINGÜÍSTICA } \\
\text { APLICADA }\end{array}$ & 5 & 5 \\
\hline LETRAS & $\begin{array}{l}\text { UNIVERSIDADE EST.PAULISTA JÚLIO DE } \\
\text { MESQUITA FILHO/ASSIS }\end{array}$ & $\begin{array}{c}\text { LETRAS / } \\
\text { LINGUÍSTICA } \\
\end{array}$ & LETRAS & 5 & 5 \\
\hline Letras & $\begin{array}{l}\text { UNIVERSIDADE ESTADUAL DO OESTE } \\
\text { DO PARANA }\end{array}$ & $\begin{array}{l}\text { LETRAS / } \\
\text { LINGUÍSTICA }\end{array}$ & Letras & 5 & 5 \\
\hline LITERATURA E CULTURA & UNIVERSIDADE FEDERAL DA BAHIA & $\begin{array}{l}\text { LETRAS / } \\
\text { LINGUÍSTICA }\end{array}$ & LETRAS & 5 & 5 \\
\hline LETRAS E LINGUÍSTICA & UNIVERSIDADE FEDERAL DE GOIÁS & $\begin{array}{c}\text { LETRAS / } \\
\text { LINGUÍSTICA } \\
\end{array}$ & $\begin{array}{c}\text { LETRAS E } \\
\text { LINGUÍSTICA } \\
\end{array}$ & 5 & 5 \\
\hline LITERATURA & $\begin{array}{l}\text { UNIVERSIDADE FEDERAL DE SANTA } \\
\text { CATARINA }\end{array}$ & $\begin{array}{c}\text { LETRAS / } \\
\text { LINGUÍSTICA }\end{array}$ & LETRAS & 5 & 5 \\
\hline LETRAS & $\begin{array}{l}\text { UNIVERSIDADE FEDERAL DE SANTA } \\
\text { MARIA }\end{array}$ & $\begin{array}{l}\text { LETRAS / } \\
\text { LINGUÍSTICA }\end{array}$ & LETRAS & 5 & 5 \\
\hline $\begin{array}{l}\text { LETRAS: LINGÜÍSTICA E } \\
\text { TEORIA LITERÁRIA }\end{array}$ & UNIVERSIDADE FEDERAL DO PARÁ & $\begin{array}{c}\text { LETRAS / } \\
\text { LINGUÍSTICA }\end{array}$ & $\begin{array}{l}\text { LETRAS: LINGÜÍSTICA } \\
\text { E TEORIA LITERÁRIA }\end{array}$ & 5 & 5 \\
\hline $\begin{array}{l}\text { LETRAS (CIÊNCIA DA } \\
\text { LITERATURA) }\end{array}$ & $\begin{array}{l}\text { UNIVERSIDADE FEDERAL DO RIO DE } \\
\text { JANEIRO }\end{array}$ & $\begin{array}{c}\text { LETRAS / } \\
\text { LINGUÍSTICA } \\
\end{array}$ & TEORIA LITERARIA & 5 & 5 \\
\hline
\end{tabular}

Fonte: Capes. 


\section{A escrita criativa como área de concentração, linha de pesquisa ou disciplina}

Iniciou-se esta pesquisa buscando que instituições que tivessem linhas de pesquisa ou áreas de concentração com os termos "escrita criativa", "criação literária", "oficina", "formação de escritores" ou "produção textual" em seu título nos cursos de pós-graduação strictu sensu supra listados.

A Pontifícia Universidade Católica (PUCRS), já reconhecida pelo seu pioneirismo no tema (ASSIS BRASIL, 2015), foi a única que apresentou o termo "Escrita Criativa" como área de concentração do Programa de Pós-Graduação em Letras, ao lado das áreas de Linguística e Teoria da Literatura.

A área de ESCRITA CRIATIVA, com ênfase interdisciplinar, tem uma linha de pesquisa específica: Leitura, Criação e Sistema Literário. Investiga a gênese de textos literários e não literários, sua relação com outras linguagens, a inclusão do escritor no sistema literário, apoiada em teorias críticas da literatura e em documentos de escritores sobre o processo de criação. Seu foco volta-se à criação literária e seus fundamentos estéticos, à crítica genética, às relações entre literaturas e outras mídias, produção de roteiros teatrais e fílmicos e criação de textos não literários. Os acervos literários e documentais do DELFOS - Espaço de Documentação e Memória Cultural - estão à disposição para investigação e aulas in loco sobre o processo criativo dos escritores através do manuseio e da análise dos manuscritos, correspondências, fotografias e anotações registradas em livros e outros materiais que integram o Espaço (PUCRS, 2017, sem paginação)
Duas linhas de pesquisa estão relacionadas à Escrita Criativa no site da instituição, "Fundamentos Linguístico-Literários da Linguagem" (esta compartilhada com a área de Teoria da Literatura) e "Leitura, Criação e Sistema Literário". Essa segunda linha de pesquisa é exclusiva da Escrita Criativa e "agrupa os projetos que discutem a gênese de textos literários e não literários, sua relação com outras linguagens, bem como a inclusão da figura do escritor no sistema literário, apoiada em teorias críticas da literatura e em documentos de escritores sobre o processo de criação"2.

Além da PUCRS, apenas na Universidade Federal do Rio Grande do Sul (Ufrgs) há outra recorrência dos termos pesquisados, dessa vez como linha de pesquisa, não como área de concentração. Trata-se da linha de pesquisa "Estudos literários aplicados: Literatura, Ensino e Escrita criativa", uma das cinco linhas da área de concentração Estudos de Literatura. Na própria ementa da linha, porém, notamos que a escrita criativa está junto com outros temas bastante diversos, como ensino de literatura, representação da leitura, literatura contemporânea e crítica genética:

Ensino e difusão da literatura no plano da escola e da sociedade, considerando a formação do leitor. Representações da leitura. Literatura contemporânea em suas diversas manifestações. Proposta de novas práticas discursivas no âmbito da oralidade e da escrita. Processo de criação em diferentes dimensões, tanto no sentido da produção de uma obra ficcional própria quanto no sentido do estudo do processo de criação de outro autor. Tal estudo pode se dar a partir de documentos de processo (crítica genética), a partir da obra publicada, a partir de correspondências e de entrevistas. ${ }^{3}$ 
Ainda segundo o próprio site da instituição, há apenas duas disciplinas específicas nesta linha de estudo, "Estudos de Literatura contemporânea" e "Teorias do processo criativo", e nenhuma obrigatória. Não há ementa delas no site, mas chama a atenção que é a linha de pesquisa com menor número de disciplinas específicas a ela vinculadas. ${ }^{4}$

Ampliando um pouco os critérios, buscou-se identificar outros programas que possam estar trabalhando com a escrita criativa, mesmo sem usar o termo em uma área de concentração ou linha de pesquisa, e assim chegou-se a outros seis programas.

No Programa de Pós-Graduação em Estudos Literários da UFMG, dentre as 7 linhas de pesquisa encontra-se uma chamada "Edição e recepção de textos literários", que trabalha com o "estudo do texto literário e de sua recepção, do ponto de vista de sua gênese, da preparação de originais, edições, paratextos, comentários, críticas e interpretações". ${ }^{5}$ Embora não tenha as palavras-chave estipuladas, menciona gênese do texto literário, preparação de originais e edição, atividades mais voltadas à escrita e produção editorial do que à análise literária. As disciplinas listadas, porém, seguem o padrão mais tradicional e não mencionam palavras-chave como "produção", "escrita", "gênese", "recepção", "originais" ou "criativa", nem se buscadas separadamente. ${ }^{6}$

$\mathrm{Na}$ Pontifícia Universidade Católica de Minas Gerais também encontramos uma linha de pesquisa que permitiria $o$ trabalho com a escrita criativa dentro da área de concentração Literaturas de Língua Portuguesa: "Texto, gênese e memória". A linha é descrita como "estudo de textos das literaturas de língua portuguesa e sua gênese, com vistas à crítica textual, à produção de edições, sua recepção crítica e ficcional e sua recuperação para a historiografia literária" [grifos nossos]. ${ }^{7}$

Observando as disciplinas indicadas para o segundo semestre de 2017, como uma das optativas há a disciplina "Dimensões do poético - ler e fazer", que traz em sua ementa: "Leitura, análise e interpretação de contos e poemas. Estratégias de produção de um texto, a partir da recepção. $O$ escritor e seus processos criativos. Cena literária contemporânea: fronteiras da criação." Inclusive na bibliografia indicada está o livro "A escrita criativa: pensar e escrever literatura", editado pela EDIPUCRS. ${ }^{9}$

Também na Pontifícia Universidade Católica, desta vez no Rio de Janeiro, dentro da área de concentração Literatura, Cultura e Contemporaneidade há uma linha de pesquisa chamada "Novos cenários da escrita".

A Linha de Pesquisa reúne investigações voltadas para a noção sedimentada de escrita, entendendo-a não apenas no âmbito textual, mas também nas dimensões visual, plástica, tátil e auditiva, tanto no interior de um sistema artístico, quanto de um sistema de práticas sociais específicas. Seu foco destaca experiências-limite e/ou transversais que resistem aos processos significativos instituídos, interrogando as práticas tradicionais de interpretação e de comunicação. Desse modo, essa noção de escrita vem acentuar a potência performativa da experiência estética ao privilegiar uma visão não dicotômica entre corpo e sentido, fundo e superfície, força e forma. ${ }^{10}$ 
Embora trabalhando com um conceito de escrita mais amplo, que abre espaço para a intertextualidade e a aproximação com outras artes e áreas do conhecimento, na relação de disciplinas do programa há disciplinas como "Novos suportes da escrita", "A 'escrita de si' na comunicação literária", "Escrita artística e produção de pensamento", "Escrita e cultura contemporânea", "Tópicos em teorias do texto e da escrita" e "Literatura e política: a performance intelectual do escritor na modernidade".

Segundo a ementa, a disciplina "A 'escrita em si' na comunicação literária" trabalha com "discursos autobiográficos e autoficcionais contemporâneos. Novos repertórios literários e teóricos de escritas de si. (...) Histórias de literatura no limiar entre escrita de memória, biografia, autobiografia, ficção e autoficção. Experimentos autobiograficcionais”. E a disciplina "Escrita e cultura contemporânea” aborda “(...) a produção de diferentes escritas conectadas em rede. Os questionamentos e transformações do conceito de escrita". ${ }^{11}$

No Programa de Pós-Graduação em Literatura da UnB há a linha de pesquisa "Textualidades: da leitura à escrita", cujo objetivo é o "estudo teórico das condições plurissignificativas de textos literários. Da gênese textual à recepção contextualizada. Entrelaçamento entre o tecido textual e as diferentes práticas de leituras". ${ }^{12}$ Entre as disciplinas atuais ou antigas do curso, encontramos disciplinas como "Escritas de Si", "Políticas da Escrita" e "Leitura e Escrita". A ementa desta última, pela sua amplitude, permitiria um trabalho com escrita criativa: "Estudo aprofundado de uma ou de ambas as práticas culturais produtoras de sentido, a partir de um ou mais dos seguintes eixos: conceitual, sócio-político e pedagógico. Estudo das relações entre a história da imprensa escrita e os diferentes modos de leitura". ${ }^{13}$

No Programa de Pós-Graduação em Letras da UPF, conhecida nacionalmente por organizar a Jornada de Literatura de Passo Fundo, que rendeu à cidade o título de Capital Nacional da Literatura (SENADO, 2005), há uma linha de pesquisa com foco na produção do texto literário, "Produção e recepção do texto literário":

Estudo das condições de produção e recepção do texto literário, focalizando o processo de criação e de interpretação da obra literária e examinando a atividade da crítica literária nesse sistema. Considera o conceito de instituição literária postulado por Julia Kristeva, em que se destacam dois aspectos: o da própria literatura, a prática da escrita e o fato de esta inserir-se num código que consiste em transpor, a partir de certo número de imposições, uma experiência imaginária ou real; e aquele configurado pelas margens da prática literária, como as revistas, os júris, a academia, tudo o que consagra a experiência literária e lhe dá uma possibilidade de chegar ao público. ${ }^{14}$

Observando os projetos de pesquisa ligados à linha, porém, não encontramos nos títulos nem nas descrições os termos "escrita criativa", "produção", "criação", ficando o estudo ainda mais restrito aos processos de produção do que à produção ou à escrita em si. 
No programa de Pós-Graduação em Estudos Literários da UNESP - Campus de Araraquara, dentro da linha de pesquisa "Teorias e Crítica do Drama" está previsto "estudo dos procedimentos de produção textual e cênica a partir da teoria teatral e de concepções estéticas variadas" [grifo nosso], mas restrito a textos do gênero drama. As linhas de pesquisa "Teoria e Crítica da Narrativa" e "Teoria e Crítica da Poesia" não trazem a palavra "produção" na sua ementa, apenas o "estudo de teorias". ${ }^{15}$

\section{Teses e dissertações sobre escrita criativa}

Outro indicador possível para se mapear a presença da Escrita Criativa nos cursos de pós-graduação strictu sensu brasileiros é o Banco de Teses e Dissertações da CAPES. ${ }^{16}$ Ao fazer uma busca pelo termo "escrita criativa", retornou 156 resultados.

Figura 1 - Tela do Banco de Teses e Dissertações da CAPES

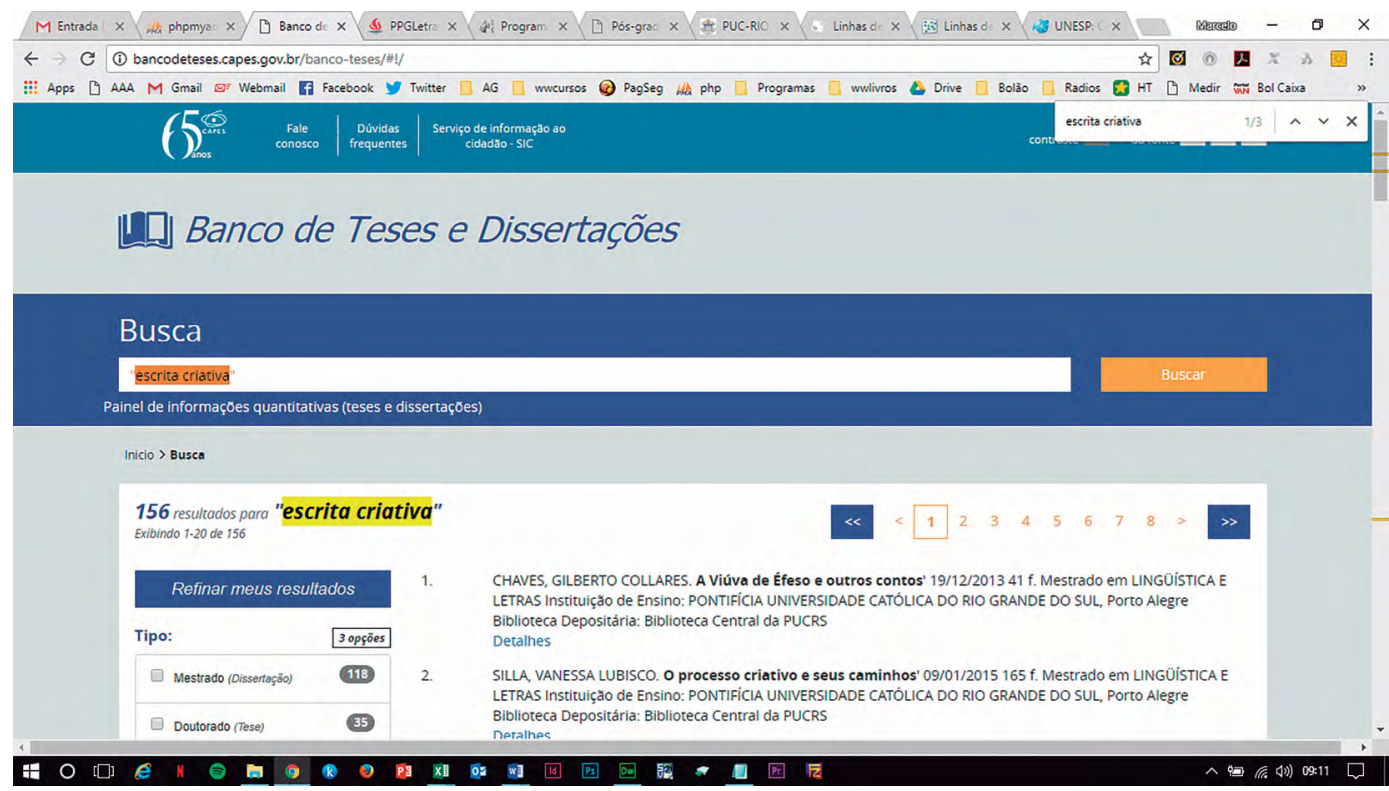


Basta uma olhada mais atenta aos títulos e programas, porém, para repararmos que nem todos os trabalhos são de fato da escrita criativa, misturando-se com trabalhos de análise, teoria, etc. Desta forma, buscamos trabalhos em que a expressão "escrita criativa" aparecesse nos títulos, identificando nove trabalhos (reproduzimos na ordem e no formato que apareceu na plataforma):

Flandoli, Beatriz Rosália Gomes Xavier. A escrita criativa do ensino fundamental: uma interlocução possível' 01/09/2003 191 f. Mestrado em EDUCAÇÃO Instituição de Ensino: FUNDAÇÃO UNIVERSIDADE FEDERAL DE MATO GROSSO DO SUL, CAMPO GRANDE Biblioteca Depositária: Biblioteca Central da UFMS

SIQUEIRA, YAN PATRICK BRANDEMBURG. Oficina literária de escrita criativa' 16/03/2016 128 f. Mestrado em LETRAS Instituição de Ensino: UNIVERSIDADE FEDERAL DO ESPÍRITO SANTO, Vitória Biblioteca Depositária: Biblioteca Central da Ufes

Azevedo, Cristiane dos Santos. Escrita criativa em sala de aula do EJA - efeitos sobre a produção textual dos alunos' 01/09/2007 167 f. Mestrado em EDUCAÇÃO Instituição de Ensino: UNIVERSIDADE FEDERAL DE PELOTAS, PELOTAS Biblioteca Depositária: Biblioteca Setorial das Ciências Sociais

PEIXOTO, SOLANGE ESTER LIMA. LITERATURA INFANTO-JUVENIL NO ENSINO FUNDAMENTAL: Releitura e Escrita Criativa de Contos' 28/04/2014 146 f. Mestrado em LINGÜÍSTICA APLICADA Instituição de Ensino: UNIVERSIDADE DE TAUBATÉ, Taubaté Biblioteca Depositária: Depto. Ciências Sociais e Letras

JUNQUEIRA, PATRICIA CORREA. Processos Interacionais: da leitura à escrita criativa' 14/09/2015 $113 \mathrm{f}$. Mestrado em EDUCAÇÃO, LINGUAGEM E TECNOLOGIAS
Instituição de Ensino: UNIVERSIDADE ESTADUAL DE GOIÁS, Anápolis Biblioteca Depositária: Câmpus Anápolis CSEH

Gazola, Naulise Castro Alves. Escrita Criativa e Devaneios: Cartas de Kafka e Caio F.' 01/05/2012 83 f. Mestrado em LETRAS Instituição de Ensino: CENTRO UNIVERSITÁRIO RITTER DOS REIS, Porto Alegre Biblioteca Depositária: Biblioteca Romeu Ritter dos Reis

MANTOVANI, FATIMA APARECIDA. LEITURA E ESCRITA CRIATIVA NOS ANOS FINAIS DO ENSINO FUNDAMENTAL' 16/11/2016 224 f. Mestrado Profissional em LETRAS Instituição de Ensino: UNIVERSIDADE ESTADUAL DO NORTE DO PARANÁ, Natal Biblioteca Depositária: UENP

Angelo, Darlene Vianna Gaudio. A erótica da narrativa: a escrita criativa de Ana Maria Machado' 01/03/2004 $161 \mathrm{f}$. Mestrado em LETRAS Instituição de Ensino: UNIVERSIDADE FEDERAL DO ESPÍRITO SANTO, VITÓRIA Biblioteca Depositária: Biblioteca do PPGL/MEL e Biblioteca Central

BOTELHO, ANDRÉA PACETTA DE ARRUDA. Tramas que sustentam transformações: escrita criativa e autodesenvolvimento como aliados na construção de perfis e histórias de vida em jornalismo literário' 01/05/2004 396 f. Doutorado em CIÊNCIAS DA COMUNICAÇÃO Instituição de Ensino: UNIVERSIDADE DE SÃO PAULO, São Paulo Biblioteca Depositária: ECA/USP

Chama a atenção que não há nenhum trabalho das instituições citadas anteriormente neste artigo, o que revela, evidentemente, que nem todos os trabalhos sobre escrita criativa colocam o termo no título, motivo pelo qual não foram considerados nessa busca. É salutar, porém, observar que o termo e o tema têm surgido eventualmente em diferentes instituições e diferentes momentos. 
Os nove trabalhos aqui listados são de oito instituições diferentes (apenas a Universidade Federal do Espírito Santo tem dois trabalhos), compreendendo instituições do Nordeste, Centro, Sudeste e Sul; privadas, estaduais e federais. Em relação ao ano dos trabalhos, o primeiro listado é de 2003 e os dois mais recentes de 2016, sendo que também foram dois trabalhos listados como de 2004. Apenas um trabalho é de Doutorado (de 2004, da USP), os demais são de Mestrado.

Chama a atenção, ainda, o potencial interdisciplinar do tema: dois trabalhos são de programas da Educação, um da Comunicação, um da Linguística Aplicada, quatro da Letras e um de um programa interdisciplinar.

\section{Considerações finais}

Por mais frustrante que seja, um pesquisador precisa reconhecer quando sua hipótese inicial de trabalho não foi confirmada, e parece claramente o caso desta pesquisa. Iniciamos afirmando que a discussão sobre oficinas de escrita criativa - e por extensão sobre cursos universitários de escrita criativa - já passara da primeira fase no Brasil, quando se questionava a possibilidade de alguém aprender algo tão "intuitivo" quanto escrever um bom texto literário. Mas avaliando os resultados da nossa pesquisa sobre a presença da escrita criativa nos cursos de pós-graduação strictu sensu das universidades brasileiras, parece que ainda há, sim, dificuldade em entender a criação literária como um processo passível de ser pesquisado, ensinado e aprendido.

Apenas um dos 28 programas de pós-graduação analisados têm uma área de concentração em Escrita Criativa (PUCRS), e apenas mais um tem uma linha de pesquisa com o termo no seu título (UFRGS). O curioso é que nem o termo "produção textual" aparece nos títulos das áreas de concentração ou linhas de pesquisa, o que pode indicar não uma dificuldade de se trabalhar com a escrita criativa nos cursos de pós-graduação strictu sensu no Brasil, e sim uma dificuldade de se trabalhar com a escrita como um todo.

Parte dessa dificuldade pode estar relacionada com a persistente crença de que a escrita é um dom restrito a gênio iluminados. Os próprios escritores contemporâneos por vezes alimentam essa visão romântica. Stephen King, em Sobre a Escrita, aborda frontalmente o tema das oficinas de escrita criativa, partindo de um romance, Oriente, Oriente, para ironizar especificamente os retiros de creative writing, comuns nos Estados Unidos. Adiante, o escritor admite "certo preconceito", fundamentando sua crítica às oficinas com sua experiência pessoal: "uma das poucas vezes em que sofri um sério bloqueio criativo foi durante meu último ano na Universidade do Maine, quando fiz não um, mas dois cursos de escrita criativa (o primeiro foi o seminário em que conheci minha mulher, então não dá para dizer que foi tempo perdido)" (2015, p. 199). Por fim, o autor conclui: 
Você não precisa de cursos ou seminários de escrita mais do que precisa deste livro ou de qualquer outro sobre o assunto. Faulkner aprendeu seu ofício enquanto trabalhava na agência de correio de Oxford, Mississippi. Outros escritores aprenderam o básico enquanto serviam na Marinha, trabalhavam em siderúrgicas ou passavam uma temporada nos melhores hotéis com janelas de grade dos Estados Unidos. Eu aprendi a parte mais valiosa (e comercial) de meu trabalho enquanto lavava lençóis de motel e toalhas de mesa na lavanderia New Franklin, em Bangor. Aprendemos mais lendo muito e escrevendo muito, e as lições mais valiosas são aquelas que ensinamos a nós mesmos. São lições que quase sempre nos ocorrem quando a porta do escritório está fechada. As discussões levantadas em cursos de escrita podem ser muito divertidas e intelectualmente estimulantes, mas costumam ficar bem distantes do laborioso ofício de escrever. (2015, p. 201-202)

O escritor português Mario de Carvalho, em Quem disser ao contrário é porque tem razão: guia prático de escrita de ficção, já no primeiro capítulo denuncia os "livros ditos de autoajuda que pretendem ensinar os novos autores a escrever" (2014, p. 15) e adiante afirma: "pensar que se fica apto a escrever depois de ler um compêndio de escrita criativa é o mesmo que julgar se passa a dominar a língua após ter comprado um dicionário" (2014, p. 18). É curioso que o escritor é, ele próprio, ministrante de oficinas de escrita, mas afirma nunca as ter chamado de "criativa": "sempre me pareceu que isso de criação (se não nos referirmos a panarícios ou capoeiras) não se dissemina, nem é transmissível" (2014, p. 19).
Rosa Montero, em A louca da casa, não aborda diretamente o ensino da escrita criativa, mas simboliza essa visão romântica ao afirmar que escrever ficção é expor à luz um fragmento muito profundo do inconsciente: "Quero dizer que ambas as coisas, sonhos e romances, surgem do mesmo estrato da consciência. Algumas vezes, aliás, os autores sonharam literalmente suas criações" (2008, p. 85-86). E Haruki Murakami, em Do que eu falo quando falo de corrida, chega a afirmar que "a maior parte do que sei sobre escrever, aprendi correndo todos os dias" (2010, p. 72)

Por outro lado, ao se fazer um balanço sobre a Oficina de Criação Literária da PUCRS, por exemplo, observa-se que

[...] já passaram mais de setecentos alunos, e vários destes vêm obtendo relevantes prêmios e indicações de certames de caráter nacional, como o Portugal Telecom, São Paulo e Jabuti, e têm publicado pelas mais importantes editoras nacionais e internacionais (ASSIS BRASIL, 2015, p. 109).

É sintomático também, ainda que tímido, o surgimento de teses e dissertações com o termo "escrita criativa" no título em variadas instituições, programas e época. Sem contar o Prêmio Nobel atribuído a Kazuo Ishiguro, que fez mestrado em Escrita Criativa na Universidade de East Anglia (G1, 2017) e tornou-se o primeiro escritor com estudo formal na área a receber o Prêmio.

Resta-nos, como pesquisador, seguir investigando a presença da escrita criativa nas universidades, agora no âmbito da graduação e dos cursos de pós-gradua- 
ção lato sensu, para tentar compreender por que no Brasil, ao contrário dos Estados Unidos, o espaço da escrita criativa no meio acadêmico seja tão tímido.

\section{Creative writing in stricto sensu postgraduate courses in brazilian universities}

\section{Abstract}

An increasing demand for courses and books about creative writing has been seen in Brazil over the last decade. Nonetheless, investigating whether this increasing demand is reflected in a wider presence in Brazilian universities was still needed, specifically in stricto sensu postgraduate courses, where most research and knowledge production takes place in Brazil. For the purpose of this work, 28 postgraduate programs were analyzed, all of them presenting an upper 5 grade in the 2017's Quadrennial CAPES Evaluation. Also, works that had the expression "creative writing" in their title were searched at CAPES' Theses and Dissertations Bank. Finally, the initial hypothesis of the growth of formal presence was frustrated, which may be related to the persistent belief of writing being a restricted gift to enlightened geniuses.

Keywords: Creative writing. Creative writing education. Creative writing in Brazilian universities.

\section{Notas}

1 Disponível em: <http://www.capes.gov.br/ sala-de-imprensa/noticias/8557-divulgado-o-resultado-da-1-etapa-da-avaliacao-quadrienal-2017>. Acesso em: 06 dez. 2017.

2 Disponível em: <http://www.pucrs.br/humanidades/programa-de-pos-graduacao-em-letras/ linhas-e-estruturas-de-pesquisa-equipe-corpo-docente-disciplinas-teses-e-dissertacoes-informacoes-adicionais-informacoes-financeiras-fale-conosco-english-website-pagina-web-en-espanol-apresentacao-hi/>. Acesso em: $06 \mathrm{dez}$. 2017.

3 Disponível em: <https://www.ufrgs.br/ppgletras/linhasdepesquisa.html>. Acesso em: 06 dez. 2017.

4 Disponível em: <https://www.ufrgs.br/ppgletras/pdf/DisciplinasPorLinhadePesquisa.pdf $>$. Acesso em: 06 dez. 2017.

5 Disponível em: <http://poslit.letras.ufmg.br/ pt-br/linhas-e-projetos-de-pesquisa/linhas-de-pesquisa>. Acesso em: 06 dez. 2017.

6 Disponível em: <http://poslit.letras.ufmg.br/ pt-br/disciplinas/grade-curricular $>$. Acesso em: 06 dez. 2017.

7 Disponível em: <http://portal.pucminas.br/ pos/letras/index-link.php?arquivo=linha\&pagina $=4172 \&$ codigo $=37 \& i d=93>$. Acesso em: 06 dez. 2017.

8 Disponível em: <http://portal.pucminas.br/pos/ letras/index-link.php?arquivo=disciplina\&pagina $=4173 \&$ codigo $=37>$. Acesso em: $06 \mathrm{dez}$. 2017.

9 Disponível em: <http://portal.pucminas.br/ imagedb/mestrado_doutorado/disciplinas/ DIS_ARQ_DISCI20170317105523.pdf>. Acesso em: 06 dez. 2017.

10 Disponível em: <http://www.puc-rio.br/ensinopesq/ccpg/proglet_literatura.html\#linhas >. Acesso em: $06 \mathrm{dez} .2017$.

11 Disponível em: <http://www.puc-rio.br/ensinopesq/ccpg/proglet_literatura.html\#ementas>. Acesso em: 06 dez. 2017.

12 Disponível em: <http://poslit.unb.br/?page id=399>. Acesso em: $06 \mathrm{dez} .2017$.

13 Disponível em: <http://poslit.unb.br/wp-content/uploads/Todas-as-disciplinas-do-Poslit-Novas-e-antigas.pdf>. Acesso em: $06 \mathrm{dez} .2017$.

14 Disponível em: <http://www.upf.br/ppgl/linhas-de-pesquisa-e-projetos $>$. Acesso em: $06 \mathrm{dez}$. 2017. 
15 Disponível em: <http://www.fclar.unesp.br/\#!/ pos-graduacao/stricto-sensu/estudos-literarios/ linhas-de-pesquisa/>. Acesso em: 06 dez. 2017.

16

Disponível em: <http://bancodeteses.capes.gov. br/banco-teses/\#!/>. Acesso em: 06 dez. 2017.

\section{Referências}

ASSIS BRASIL, Luiz Antonio. "A escrita criativa e a universidade". Revista Letras de Hoje, dez. 2015. Disponível em: <http:// revistaseletronicas.pucrs.br/ojs/index.php/ fale/article/viewFile/23146/14076>. Acesso em: 03 fev. 2017.

CARVALHO, Mario de. Quem disser o contrário é porque tem razão: letras sem tretas: guia prático de escrita de ficção. Porto: Porto Editora, 2014. 275 p.

FORNER, Juliana. PUCRS passará a oferecer curso superior de tecnologia em Escrita Criativa a partir de 2016. 2015. Disponível em: <http://zh.clicrbs.com.br/rs/vida-e-estilo/ educacao/noticia/2015/09/pucrs-passara-a-oferecer-curso-superior-de-tecnologia-em-escrita-criativa-a-partir-de-2016-4838974. html/>. Acesso em: 06 dez. 2017.

G1. Kazuo Ishiguro ganha o Prêmio Nobel de Literatura de 2017. 2017. Disponível em: $<$ https://g1.globo.com/pop-arte/noticia/kazuo-ishiguro-ganha-o-premio-nobel-de-literatura-2017.ghtml>. Acesso em: 16 dez. 2017.

GUEDES, Diogo. A ainda tímida relação entre cursos de Letras e a escrita criativa. 2014. Disponível em: <http://jconline.ne10. uol.com.br/canal/cultura/literatura/noticia/2014/03/16/ a-ainda-timida-relacao-entre-cursos-de-letras-e-a-escrita-criativa-121472. php>. Acesso em: 06 dez. 2017.

KING, Stephen. Sobre a escrita. Trad. Michel Teixeira. Rio de Janeiro: Objetiva, 2015. 255 p.

LIMA, Marcelo. Cursos de pós-graduação prometem formar escritores. 2014. Disponível em: <http://educacao.estadao.com.br/ noticias/geral,cursos-de-pos-graduacao-prometem-formar-escritores,1588977>. Acesso em: 06 dez. 2017.

MINISTÉRIO DA EDUCAÇÃO. Fundação Capes. Cursos Recomendados / Reconhecidos. 2014. Disponível em: <http://www.capes.gov. br/cursos-recomendados>. Acesso em: 06 dez. 2017.

MONTERO, Rosa. A louca da casa. Trad. Paulinha Watch e Ari Roitman. Rio de Janeiro: Agir, 2008. 196 p.

MURAKAMI, Haruki. Do que eu falo quando falo de corrida. Trad. Cássio de Arantes Leite. Rio de Janeiro: Objetiva, 2010.

PUCRS. Programa de pós-graduação em Letras. s/d. Disponível em: <http://www.pucrs. $\mathrm{br} /$ humanidades/programa-de-pos-graduacao-em-letras/>. Acesso em: 06 dez. 2017.

SENADO Notícias. Passo Fundo é declarada capital nacional da literatura. 2005. Disponível em: <https://www12.senado.leg. br/noticias/materias/2005/12/14/passo-fundo-e-declarada-capital-nacional-da-literatura>. Acesso em: 06 dez. 2017.

TERRA. Universidades integram oficinas de escrita criativa ao currículo. 2012. Disponível em: <https://noticias.terra.com.br/educacao/ universidades-integram-oficinas-de-escrita-criativa-ao-curriculo,b40ddc840f0da310VgnCLD200000bbcceb0aRCRD.html>. Acesso em: 06 dez. 2017.

UFPE. Estímulo à criação ainda precisa evoluir. s/d. Disponível em: < https://www. ufpe.br/agencia/clipping/index.php?option=com_content\&view=article\&id=16189:estimulo-a-criacao-ainda-precisa-evoluir\&cati$\mathrm{d}=30 \&$ Itemid=122>. Acesso em: $06 \mathrm{dez} .2017$. 